\title{
$O$ podcast como gênero discursiwo: oralidade e multissemiose aquém $e$ além da sala de aula
}

The podcast as a discursive genre: orality and multisemiosis below and beyond the classroom

Marco Antonio Villarta-Neder

Universidade Federal de Lavras - UFLA

Helena Maria Ferreira

Universidade Federal de Lavras - UFLA

DOI: https://doi.org/10.5902/2176148539579

\begin{abstract}
Resumo: Os podcasts constituem-se como gênero discursivo oral e apresentam desafios conceituais e metodológicos para o emprego de tecnologias do mundo digital em sala de aula, assim como para refletir-se sobre contextos educacionais não escolares. 0 objetivo deste artigo é discutir as potencialidades e implicações teóricas, metodológicas, epistemológicas e axiológicas do gênero discursivo podcast como prática educacional. Para isso, utilizamos o referencial do Círculo de Bakhtin, especificamente, com os conceitos de gênero discursivo, enunciado e tom. Analisar os podcasts pode contribuir para enriquecer a compreensão dos gêneros discursivos orais, sua complexa relação com a escrita e com as outras semioses.
\end{abstract}

Palavras-chave: Oralidade. Multissemiose. Gêneros discursivos.

Abstract: Podcasts constitute an oral discursive genre and present conceptual and methodological challenges for the use of digital technologies in the classroom, as well as for reflecting on non-school educational contexts. The aim of this paper is to discuss the theoretical, methodological, epistemological and axiological potentialities and implications of the discursive genre podcast as an educational practice. For this, we use the Bakhtin Circle framework, specifically with the concepts of discursive genre, utterance and tone. Analyzing podcasts can contribute to improve the understanding of oral discursive genres, their complex relation to writing and other semiosis.

Keywords: Orality. Multissemiosis. Discursive genres. 
Marco Antonio

Villarta-Neder

Helena Maria

Ferreira

\section{Introdução}

A tradição ocidental de estudos da/sobre a linguagem funda-se em uma constante tensão e mútua constitutividade entre as duas modalidades da língua - oralidade e escrita - e, desde o início com algum grau de diálogo entre a língua e outras linguagens. No contexto helênico e helenístico, tais diálogos priorizaram, de um lado, a dimensão ética de como a palavra - o lógos - e sua compreensão, em uma justa medida, tornaria o ser humano capaz de atingir a verdade, e de outro, a dimensão estética da arte, como (re)criação do mundo. Para a cultura helênica e helenística, não havia o interesse pela língua(gem) cotidiana - léxis - necessária para os fazeres práticos - mas, do ponto de vista dessas culturas, pouco proveitosa para a construção de uma cosmologia minimamente confiável.

A partir de uma reformulação dessas abordagens, na nossa sociedade, um dos conceitos que sustentam essa rede conceitual é o de gêneros. Inicialmente, concebidos para dar conta das fronteiras entre a retórica, a lógica e a crítica dos textos basilares dos valores da cultura desses povos da Antiguidade Clássica (considerando-se que os romanos foram herdeiros importantes, seja pela continuidade, difusão, seja por supostos reducionismos), os gêneros são rediscutidos e, principalmente, a partir das intensas transformações sociais, culturais e estéticas ocorridas na transição do século XIX para o século XX, seu conceito se amplia.

Um dos referenciais que abordaram em profundidade essa ampliação conceitual foi o Círculo de Bakhtin, designação dada a um conjunto de autores russos de variadas formações que, principalmente nas décadas iniciais do século passado, debruçaram-se sobre questões ligadas à arte, à ciência e à vida, dentro de uma concepção de indissociabilidade entre as dimensões éticas e estéticas e, especificamente no que interessa à discussão deste artigo, empreendendo uma reflexão sobre os limites e continuidades entre o oral e o escrito. Os gêneros discursivos passam a ser vistos por eles como um processo também social, cultural, o que torna imprescindível levar em conta tais âmbitos para se analisá-los.

Essa discussão chega ao Brasil em meados dos anos 1980, com a difusão de textos e conceitos do Círculo de Bakhtin. A partir do lançamento pelo MEC, no final dos anos 1990, dos Parâmetros Curriculares Nacionais, as noções de gêneros discursivos/textuais passam a constituir, mais do que um esforço de reflexão teórica, um horizonte de concepções de linguagem. É a partir desse horizonte que se almejam propostas e práticas de trabalho com a língua(gem), principalmente nas 
aulas de Língua Portuguesa, que estabeleçam um diálogo com as condições concretas nas quais os alunos se encontram, enquanto sujeitos do/ no mundo, constituindo-se na/pela linguagem.

A relevância desse olhar para com os gêneros discursivos reside de maneira ainda mais crucial pelo fato de que vivemos atualmente em um mundo sincrético, multifacetado, com relações entre práticas sociais e de linguagem que entrecruzam semioses, práticas socioculturais, modalidades da língua e níveis de acesso e participação, sendo que tudo isso se (re)constrói rápida e intensamente entre fronteiras fluidas do mundo digital e do não-digital. Entre tantos gêneros que são produzidos, circulados e recebidos, cabe apontar o podcast.

Tal gênero, presente no mundo digital, pode ser construído a partir de textos, vídeos ou áudios, sendo, no entanto, predominante a postagem de Opodcast comogênero discursivo áudios. O que ocorre - e que chama a atenção em uma discussão educacional sobre gêneros discursivos, é, em primeiro lugar, que o podcast, que surge sem um intuito pedagógico inicial, cedo já começa a ser utilizado, fora de um contexto escolar/acadêmico, para relações de ensino e de aprendizagem.

Outra característica pertinente a essa discussão é que, no caso dos podcasts em áudio, sua configuração em semiose verbal oral, sonora, não basta para defini-lo. Para ser um podcast uma postagem em áudio tem que estar hospedada em um feed de uma página de um ambiente digital $^{1}$. Ainda, caracteriza-se por uma fidelização do leitor/ouvinte, configurando uma prática social, que, entre outras questões, congrega uma comunidade de seguidores daquela página e daquele feed. Consideramos que estabelecer o recorte de nossa discussão em torno do podcast, explorando, de um lado, as implicações de seu uso educacional fora da sala de aula e, de outro, sua utilização em contextos escolares, permite abranger aspectos teóricos, metodológicos, epistemológicos e axiológicos sobre as relações entre gêneros orais em um contexto multissemiótico.

Nessa linha, dentro do escopo proposto por este dossiê temático, este artigo objetiva discutir as potencialidades e implicações teóricas, metodológicas, epistemológicas e axiológicas do gênero podcast como prática educacional, tendo em vista as intrínsecas relações com a oralidade e as potencialidades de gênero para a formação de alunos-sujeitos que se constituem na/pela linguagem.

1 Feed é um formato de dados, em forma de link, em que os usuários podem se inscrever para receberem atualizações de conteúdos e arquivos de áudio, podcasts e vídeos. 
Marco Antonio

Villarta-Neder

Helena Maria

Ferreira

\section{Implicações do conceito de gênero discursivo em um âmbito multissemiótico}

A discussão sobre gêneros discursivos implica considerarmos não somente a materialidade sígnica ou estrutura formal de um texto. Bakhtin (2011, p. 311) postula que "o acontecimento da vida do texto, isto é, sua verdadeira essência, sempre se desenvolve na fronteira de duas consciências, de dois sujeitos" (destaques do autor).

Para o Círculo, em primeiro lugar, gêneros são enunciados:

[...] o conteúdo temático, o estilo, a construção composicional estão indissoluvelmente ligados no conjunto do enunciado e são igualmente determinados pela especificidade de um campo da comunicação. Evidentemente, cada enunciado particular é individual, mas cada campo de utilização da língua elabora seus tipos relativamente estáveis de enunciados, os quais denominamos gêneros do discurso (BAKHTIN, 2016, p. 12) - destaques do autor.

Ao conceituar os gêneros do discurso como enunciados implica considerar que um "traço essencial (constitutivo) do enunciado é o seu direcionamento a alguém, o seu endereçamento" (BAKHTIN, 2011, p. 301 destaques do próprio texto). $\mathrm{O}$ autor russo ainda salienta que

\footnotetext{
Todas essas modalidades e concepções do destinatário são determinadas pelo campo da atividade humana e da vida a que tal enunciado se refere. A quem se destina o enunciado, como o falante (ou o que escreve) percebe e representa para si os seus destinatários, qual é a força e a influência deles no enunciado disto dependem tanto a composição quanto, particularmente, o estilo do enunciado. Cada gênero do discurso em cada campo da comunicação discursiva tem a sua concepção típica de destinatário que o determina como gênero (BAKHTIN, 2011, p. 301).
}

Esse viés conceitual determina nosso posicionamento teórico-epistemológico e analítico neste artigo. Analisar qualquer gênero e, especificamente, como previsto neste dossiê, gêneros orais em contexto educacionais, implica, a nosso ver, abordar minimamente esse circuito de diálogo em que se constitui o enunciado. Parafraseando Volóchinov (2013), cumpre lembrarmos que o enunciado procede de alguém e se dirige para outro alguém. 
Esses sujeitos, interdependentes e, ao mesmo tempo singulares, participam do ato de linguagem, concebida como acontecimento [sobýtie] concreto, em cuja unidade tais sujeitos se constituem e os sentidos se produzem, não como um evento isolado, mas como um elo na corrente de enunciados do Grande Tempo, considerado como um espaço semiótico da cultura em que a simultaneidade histórica de sentidos e o diálogo entre eles é possibilitado. Essa corrente enunciativa demanda considerarmos as condições sociais, históricas, culturais, ideológicas, linguageiras. Outro autor do Círculo, Pavel Medviédev, aponta essa necessidade:

Opodcast como gênero Entender um enunciado significa entendê-lo no contexto da sua contemporaneidade e da nossa (caso elas não coincidam). É necessário compreender o sentido no enunciado, o conteúdo discursivo do ato e a realidade histórica do ato em sua união concreta e interna. Sem tal compreensão, o próprio sentido estará morto, tornar-se-á um sentido de dicionário desnecessário (MEDVIÉDEV, 2012, p. 185).

Tal perspectiva interessa-nos para analisar um gênero discursivo oral, como o podcast. Analisar um gênero discursivo, assim, exige considerar essa rede de relações. No caso do podcast, implica atentar não somente para a modalidade oral, mas também para as mediações se constroem. Diferentemente de uma conversa informal, face-a-face, o podcast é uma gravação em vídeo e/ou em áudio. Embora esteja na modalidade oral, ele apresenta a possibilidade de defasagem temporal entre o ato de elocução e o ato de leitura/escuta, o que costuma ser mais característico da modalidade escrita. Nesse sentido, esse gênero nos permite ampliar a discussão sobre as características dos gêneros orais tradicionalmente elencadas por materiais didáticos que enfocam a modalidade oral.

Cabem ser considerados, ainda, outros aspectos. Se a produção, circulação e recepção de enunciados, sejam como atos de linguagem tomados especificamente, sejam eles tomados enquanto gêneros do discurso, dentro de esferas de atividade humana, os enunciados não podem prescindir desse movimento dos dizeres (de sua procedência e de seu endereçamento), então, é plausível entendermos que, semelhantemente a outros referenciais teóricos, dizer é, também, fazer. Em trabalho anterior, já adotamos essa postura: 
Marco Antonio

Villarta-Neder

Helena Maria

Ferreira

Nesse viés, em diálogo com Bakhtin (2016, p. 29), assumimos que trabalhar com enunciados não é somente analisar diálogos entre dizeres, mas diálogos entre signos de dizer, de fazer; diálogo com a compreensão como signo e do silêncio como signo de espera, como um fazer que instaura a compreensão ou responde pela escuta (sendo que esta é, sempre, ativamente responsiva) (VILLARTA-NEDER; FERREIRA; SALES, 2019, p. 141).

Tal compreensão, acreditamos, encontra respaldo em vários trabalhos de autores do Círculo. Tal definição de premissas permite-nos prosseguir com a discussão pretendida. Se pensamos na definição do podcast, deparamo-nos com algumas possibilidades definidoras. Para introduzir o problema, vamos trazer um conceito de autores que discutem o uso de podcast em contexto educacional.

É o caso de Elekaei et al. (2019), que considera que

A palavra podcast é uma combinação de palavras "iPod" e "broadcast" (Istanto, 2011). No entanto, os Podcasts podem ser reproduzidos não apenas por iPods, mas também por MP3 players e outros tipos de mídia nos computadores e dispositivos móveis. O que torna o podcasting especial é a capacidade que eles têm para "assinatura". Isso significa que os ouvintes podem se inscrever em seus podcasts favoritos por meio de um feed RSS (Really Simple Syndication). Além disso, seus computadores e telefones celulares receberão "alertas" sempre que novos episódios forem publicados. Além disso, quando o programa é aberto, os programas de software do podcatcher (usuário), como o iTunes, baixam os novos episódios automaticamente. Existem dois tipos de podcast: "podcasts de rádio" e "podcasts independentes" (ELEKAEI et al., 2019, p. 106) - tradução nossa ${ }^{2}$.

2 The word podcast is a combination of words 'iPod' and 'broadcast' [...]. However, Podcasts can be played not just by iPods but also by MP3 players and other types of media on the computers and mobile devices. What makes podcasting special is the capacity they have for 'subscription'. It means that listeners can subscribe to their favorite podcasts through an RSS (Really Simple Syndication) feed. In addition, their computers as well as mobile phones will receive 'alerts' whenever new episodes have been posted. Moreover, when the program is opened, podcatcher software programs such as iTunes will download the new episodes automatically. There are two types of podcast: 'radio podcasts' and 'independent podcasts'. 
Temos, nessa definição um conjunto de aspectos que demandam, a nosso ver, uma abordagem processual, tal qual a que adotamos. Os autores frisam que o traço definidor do podcast não é ser uma gravação em áudio, somente, mas a possibilidade de subscrição, de assinatura, o que constrói uma vinculação à página dentro da qual o podcast está hospedado. Usuários e navegantes digitais conhecem bem as decorrências. Tal vinculação congrega usuários, cria comunidades de interesse, impulsiona (inclusive, às vezes, comercialmente) as páginas, participa como um dos níveis de hiperlink do mundo digital.

As tecnologias utilizadas (tanto os aplicativos/softwares, quanto os dispositivos de hardware que suportam tais programas) constituem formas de convivência entre sujeitos e relações desses sujeitos com campos organizados de produção, circulação e recepção de conhecimentos (analisaremos isso mais adiante).

A hospedagem dos podcasts em ambientes digitais o coloca em um contexto multissemiótico. Seria redutor e improdutivo analisar os podcasts sem essa conexão com outras semioses. Tal conceito, que vem aparecendo em variados vieses teóricos, ainda é relativamente recente no contexto bakhtiniano. Em trabalho anterior, procuramos discutir tal questão:

Embora a noção de multissemiose não apareça com essa formulação nos textos do Círculo de Bakhtin, há pontos de partida. Volóchinov (2017, p. 94) diz, por exemplo, que "Qualquer signo ideológico é não apenas um reflexo, uma sobra da realidade. Qualquer fenômeno ideológico sígnico é dado em algum material: no som, na massa física, na cor, no movimento do corpo e assim por diante." Consideramos plausível que o que o autor russo afirma a respeito de cada semiose possa ser pensado em contextos de coocorrência de várias semioses. Isso portanto, coloca, a nosso ver, em diálogo, tais concepções bakhtinianas com que outros autores, em outros referenciais, têm chamado de contextos multissemióti$\cos$ (VILLARTA-NEDER; FERREIRA; SALES, 2019, p. 131).

Além desse momento em que Volóchinov trata do signo ideológico, destacamos mais dois trechos, um de Bakhtin e outro do próprio Volóchinov que acreditamos reforçar nossa compreensão acerca da possibilidade de tratarmos teoricamente do processo multissemiótico no interior do campo do Círculo. 
Marco Antonio

Villarta-Neder

Helena Maria

Ferreira

[...] Se entendido o texto no sentido amplo como qualquer conjunto coerente de signos, a ciência das artes (a musicologia, a teoria e a história das artes plásticas) opera com textos (obras de arte). São pensamentos sobre pensamentos, vivências das vivências, palavras sobre palavras, textos sobre textos (BAKHTIN, 2011, p. 307).

Se se observa o processo de formação desses pequenos gêneros cotidianos, não é difícil notar que a comunicação verbal, em cujo âmbito eles nascem e se organizam, compõe-se de dois momentos: a enunciação feita pelo falante e sua compreensão por parte do ouvinte. Essa compreensão contém sempre os elementos da resposta. Em realidade, normalmente nós concordamos ou discordamos do que ouvimos. Habitualmente respondemos a qualquer enunciação de nosso interlocutor, se não com palavras, pelo menos com um gesto: um movimento de cabeça, um sorriso, uma pequena sacudidela da cabeça, etc. Pode-se dizer que qualquer comunicação verbal, qualquer interação verbal, se desenvolve sob a forma de intercâmbio de enunciações, ou seja, sob a forma do diálogo. Destaques do autor (VOLOCHINOV, 2013, pp. 162-163) - destaques do autor.

Como de pode ver, Bakhtin considera possível definir o texto como "qualquer conjunto coerente de signos", o que traz para o escopo de análise do conceito de texto qualquer arte, em qualquer semiose em que o processo estético se construa.

Volóchinov, ao discutir os gêneros discursivos do/no cotidiano, aponta que o circuito dialógico que constitui o enunciado, indo da procedência para o endereçamento, não se limita à semiose verbal. Podem constituir elementos desse circuito os gestos. E quando ele menciona o intercâmbio de enunciações (com ênfase dele próprio), dá margem, após ter apontado essa relação entre o verbal e os gestos, para admitirmos a possibilidade de que outras semioses também participem desse diálogo.

Tal concepção sincrética do enunciado, em termos de diálogo entre semioses, tem nos levado, em trabalhos em que analisamos textos multissemióticos, a representar tal diálogo como na figura abaixo: 


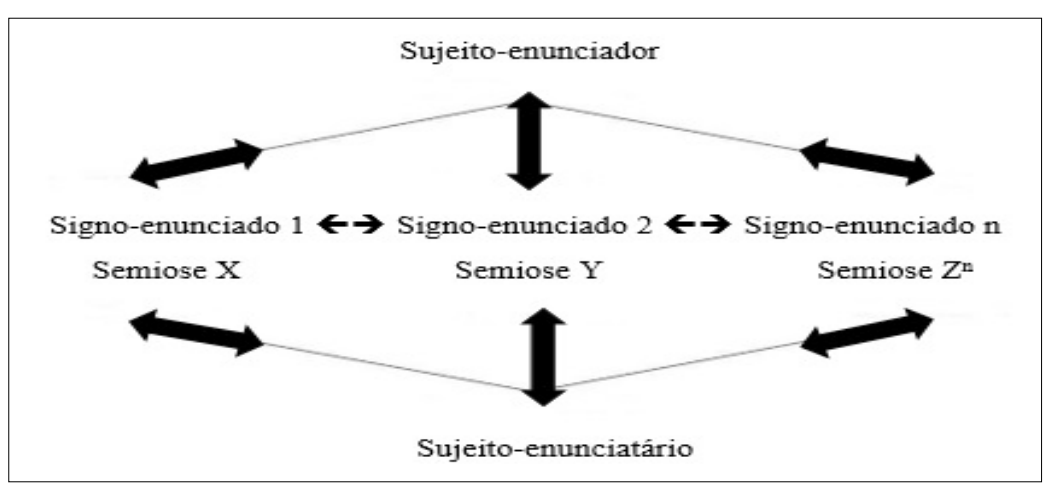

Figura 1 - Ferreira \& Villarta-Neder (2017)

Já que os enunciados se constituem por esse movimento de diálogo em relação ao que precede e ao que sucede, pode-se incorporar a essa noção a dimensão multissemiótica. A constituição dos sujeitos também depende, sempre da natureza desse diálogo entre signos, como foi dito por Bakhtin, embora em um contexto de análise de semiose verbal.

Para que se possa analisar essa relação entre sujeitos e(m) sistemas sígnicos, importa tomarmos, como já apontamos antes, nesse artigo, a indissociabilidade entre dizer e fazer. Assistir a uma aula expositiva ou ouvir o podcast da aula gravada são enunciados diferentes, não somente por diferenças de tipicidade de uma modalidade, mas, sobretudo, porque são fazeres diferentes. Essa diferença altera os sentidos do acontecimento, dos sujeitos e dos signos que constituem a materialidade semiótica do enunciado.

Para nós:
Opodcast como gênero discursivo

\begin{abstract}
Essas emaranhadas redes de signos, em inúmeras esferas de atividade humana, dialogam com o olhar inter-relacional que se tem construído para esse complexo entrelaçamento de sistemas sígnicos. Desse modo, estabelece-se um estudo das diferentes semioses, em uma perspectiva dialógica, uma vez que aprender os modos sociais de fazer é também aprender os modos sociais de dizer (VILLARTA-NEDER; FERREIRA; SALES, 2019, p. 141).
\end{abstract}

A perspectiva dialógica problematizada nesta seção buscou contextualizar as bases epistemológicas que sustentarão a discussão acerca das implicações educacionais dos podcasts. Abordar os gêneros orais, no contexto da sociedade da informação, implica considerar não somente aspec- 
Marco Antonio

Villarta-Neder

Helena Maria

Ferreira tos ligados à organização linguística dos textos, mas também os modos de produção, circulação e recepção desses textos nos múltiplos contextos.

\section{Os podcasts aquém e além da sala de aula}

Quando tratamos da maioria das novas tecnologias presentes no mundo digital, rapidamente surge a questão de que elas não foram criadas ou desenvolvidas especificamente para os ambientes digitais.

A esse primeiro aspecto, somam-se outros, igualmente importantes. Destacaremos três outros. O primeiro deles é que a aplicação desses recursos para o mundo digital, na maioria das vezes, não se constituiu como um planejamento institucional de escolas, universidades ou centros de pesquisa. O primeiro contato com várias dessas tecnologias se dá por meio do aprendiz. O segundo pode ser descrito como consequência do primeiro. Cria-se, a partir da utilização desses recursos, uma convivência de práticas educacionais que nem sempre são convergentes ou, à primeira vista, compatíveis.

O terceiro aspecto - talvez o mais relevante para análise - é de como essas novas tecnologias criam outras formas de convivência, instaurando comunidades de sujeitos com interesses comuns, com objetivos parecidos.

Revisando a bibliografia internacional sobre estudos a respeito das aplicações educacionais do podcast, encontramos um artigo, bastante referenciado nos textos mais recentes sobre o tema, que faz uma análise de 273 estudantes de uma universidade australiana, com relação aos usos do podcast e concepções/atitudes sobre ele por parte dos estudantes.

Em meio aos resultados e à discussão da pesquisa, deparamo-nos com um quadro que sintetiza os motivos pelos quais esse grupo de estudantes se utiliza do podcast. Transcrevemos tal quadro (traduzido) abaixo:

\begin{tabular}{|l|c|c|}
\hline \multirow{2}{*}{\multicolumn{1}{|c|}{ Razão }} & \multicolumn{2}{c|}{ Total } \\
\cline { 2 - 3 } & N. & \% \\
\hline Para revisar exames & 77 & 66,38 \\
\hline Para revisitar material complexo, ideias e conceitos & 71 & 61,20 \\
\hline Para trabalhar com o material no meu próprio ritmo & 60 & 51,72 \\
\hline Enfermidade de curta duração impeditiva de assistir aulas & 24 & 20.69 \\
\hline Obrigações de trabalho me impedem de comparecer & 20 & 17,24 \\
\hline Para compreender melhor a língua & 19 & 13.38 \\
\hline Difícil viajar para assistir às aulas & 16 & 13.79 \\
\hline Choque com outra aula & 10 & 8.62 \\
\hline Para ouvir informações administrativas & 4 & 3.45 \\
\hline
\end{tabular}

Figura 2 - Razões para o uso de podcasts (transcrito de Chester et al., 2011, p. 242 - tradução nossa). 
As respostas dos estudantes apontam algumas práticas com o gênero que são bem conhecidas por quem tem contato com as gerações atuais, principalmente, em contexto acadêmico.

As três primeiras são mais diretamente associadas a tarefas/fazeres acadêmicos, tais como a aplicação de exames, o estudo de conteúdos e a organização do próprio processo de aprendizagem. Cabe colocá-las, no entanto, no âmbito do viés aqui adotado. Essas/esses tarefas/ fazeres, no viés aqui adotado, estão em diálogo, são práticas socioculturais, que implicam um sujeito ativo responsivo. A ministração de aulas suscita a constituição de um conteúdo a ser estudado, que, por sua vez, demanda uma compreensão que receberá como réplica atividades de verificação de aprendizagem e uma atitude singular dos diferentes sujeitos-aprendizes.

Opodcast comogênero discursivo

Se pensarmos historicamente, no início da Universidade, em meados do ano 1000, havia a prática de o professor titular, responsável pela cadeira (cátedra) daquele campo do conhecimento, redigir por escrito sua aula, que no horário especificado, seria lida por um professor assistente. Depois da leitura, foi-se estabelecendo o costume de distribuir o texto da aula para os estudantes, que foi chamado de post illas (depois delas, das aulas) e que, em português, no cotidiano de nossas universidades e escolas, não somente passou a designar esses textos, mas ampliou seu escopo enquanto gênero discursivo para qualquer material escrito de apoio (prévio ou subsequente) às aulas.

Com o desenvolvimento de tecnologias de gravação, em imagem (cinema, seguido de tantas outras construções de signos visuais) e em áudio (som no cinema e depois gravações de sons, voz, música etc.), tais registros (ou a possibilidade deles) passaram a constituir um conjunto de práticas socioculturais que respondem, já de maneira diversa, ao gênero discursivo aula expositiva (ou conferência, palestra). Atualmente, é bastante comum, por exemplo ver, durante uma palestra, ou mesmo algumas aulas na universidade alguém gravando em áudio, filmando, fotografando. Nesse último caso, ocorre também uma transformação no próprio gênero aula.

Se anteriormente, pelo menos na universidade, um professor, responsável por aquela área do conhecimento, redigia uma aula para ser lida por outro professor, hoje é mais comum o próprio professor falar, ministrar a aula, expondo, comentando. Mais do que isso, muitas vezes, essa fala faz parte de um contexto multissemiótico, já que pode 
Marco Antonio

Villarta-Neder

Helena Maria

Ferreira

estar presente a projeção de um filme, de uma animação, de uma apresentação. Dentro desses outros gêneros que têm vindo junto com a aula oralizada, há fotografias, filmes, desenhos, escrita, sons, músicas, gravações de outras vozes.

Interessante notar que, nesse caso, há uma mudança no gênero discursivo que responde pela anotação dos estudantes, em diálogo com o gênero aula. Mais frequentemente, em vez de os alunos produzirem exclusivamente anotações escritas, eles fotografam a apresentação visual que o professor está apresentando. Isso também se tornou comum em conferências, frequentadas, muitas vezes, por pesquisadores altamente especializados.

Nos três primeiros usos mencionados na pesquisa de Chester et

alii, podem-se perceber transformações no diálogo entre esses gêneros discursivos. Os alunos vão preferindo utilizar o podcast como meio de preparação para provas e outras atividades das disciplinas que cursam em relação a anotações escritas. 0 terceiro uso é bem significativo: sugere que o ritmo da elocução da aula pode não ser compatível com o ritmo de aprendizagem do estudante.

Reitera-se que não estamos falando da gravação individual que um aluno faz de uma aula ou de uma palestra/conferência. Trata-se, enquanto podcast, de uma gravação que está hospedada em um ambiente digital. Pode ser uma página oficial da instituição universitária (ou da escola), como pode ser um site ou blog feito pelos próprios alunos. Podcasts também aparecem em sites de palestrantes ou de professores que oferecem cursos on line. Esses cursos podem ser pagos diretamente pelos alunos/assinantes ou indiretamente, pela publicidade que o site/ blog ou recurso afim angaria a partir dos assinantes do feed da página ou das visualizações e curtidas. No caso em pauta, a condição conceitual característica que o podcast tem de fidelizar os espectadores do ambiente digital introduz o diálogo com outras práticas sociais, que passam a ser também econômicas, nessa situação.

No caso dos motivos 4, 5 e 7 ("enfermidade de curta duração impeditiva de assistir aulas", "obrigações de trabalho me impedem de comparecer" e "difícil viajar para assistir às aulas"), podemos perceber que fatores relacionados às modalidades de oferecimento dos cursos (presencial, exigindo comparecimento físico) se relacionam com as práticas de ensino-aprendizagem e com as maneiras por meio das quais as práticas de linguagem participam desse diálogo. Em outras épocas, a prática era 
emprestar as anotações de colegas e copiá-las, produzindo outro texto escrito, do gênero anotação. Com a invenção e difusão das máquinas fotocopiadoras, a prática passou a ser de fazer cópia das anotações. Não deixa de ser outra forma de constituição de apostilas, com a diferença de que não são mais produzidas por quem elaborou a aula e a transcreveu. Há, portanto, uma recolocação, também, das questões de autoria e da responsabilização pelo conteúdo. A anotação é singular, pessoal. Pode ser imputada a quem anota uma compreensão equivocada da aula que assistiu, o que não se admite, inclusive do ponto de vista jurídico, se o material tiver sido fornecido pelo professor ou pela instituição de ensino.

Nos motivos 8 e 9 ("choque com outra aula" e "para ouvir informações administrativas") há um diálogo com práticas curriculares e/ou encaminhamentos quanto a isso. No motivo 8 , em uma estrutura curri-

Opodcast como gênero discursivo cular em que há conferências para um grande número de alunos (lectures), o aluno pode suprir o prejuízo de não ter assistido à aula ouvindo/ vendo o podcast e desenvolver as atividades solicitadas. No caso do motivo 9, há um pormenor interessante. Qualquer pessoa pode inteirar-se de informações administrativas por meio da leitura do site institucional. No entanto, se a pessoa dispõe de pouco tempo, pode aproveitar o tempo de deslocamento em um ônibus, táxi ou metrô para ouvir essas informações. Não costuma ser algo agradável, que a maioria das pessoas aprecie (o que talvez se reflita na pequena porcentagem de estudantes que usam o podcast por essa razão), mas, de qualquer maneira, há uma relação entre as condições de vida, trabalho, transporte, moradia que alteram as práticas desses sujeitos.

Finalmente, o motivo 6 ("para compreender melhor a língua") dialoga com situações de imigração e/ou internacionalização dos estudos, pois supõe alguém que não domine a língua nativa. Como se trata de uma universidade australiana, esse idioma é o inglês. Ficam envolvidas práticas sociais de natureza identitária, cultural, eventualmente até econômica.

Apontados esses aspectos, podemos discutir algumas implicações de natureza educacional dos podcasts enquanto gêneros discursivos orais.

Bakhtin, trata, no texto Gêneros do Discurso, das transformações pelas quais passam os gêneros primários (advindos de contextos mais íntimos e geralmente orais) até darem origem a gêneros discursivos mais complexos, não imediatamente próximos da vida, os gêneros discursivos 
Marco Antonio

Villarta-Neder

Helena Maria

Ferreira secundários. Os podcasts, como gêneros orais, poderiam levar algum analista à tentação de pensá-los como gêneros primários, já que orais.

No entanto, podcasts são gêneros que resultam de um diálogo com sofisticadas e complexas reformulações. A primeira implicação para o ensino, do ponto de vista de concepção sobre a língua é ampliar e repensar a complexa inter-relação entre as modalidades da língua: oral e escrita.

A segunda implicação que gostaríamos de destacar é que um gênero não se define exclusivamente por sua forma. Bakhtin, falando de gêneros discursivos (enquanto enunciados), nos adverte:

A expressão do enunciado, em maior ou menor grau, respon-

de, isto é, exprime a relação do falante com os enunciados do outro, e não só a relação com os objetos do seu enunciado. As formas das atitudes responsivas, que preenchem o enunciado, são sumamente diversas e até hoje não foram objeto de nenhum estudo especial. Essas formas, é claro, diferenciam-se acentuadamente em função da distinção entre aqueles campos da atividade humana e da vida nos quais ocorre a comunicação discursiva. Por mais monológico que seja o enunciado (por exemplo, uma obra científica ou filosófica), por mais concentrado que esteja no seu objeto, não pode deixar de ser em certa medida também uma resposta àquilo que já foi dito sobre dado objeto, sobre dada questão, ainda que essa responsividade não tenha adquirido uma nítida expressão externa: ela irá manifestar-se na tonalidade do sentido, na tonalidade da expressão, na tonalidade do estilo, nos matizes mais sutis da composição. $O$ enunciado é pleno de tonalidades dialógicas [...] (BAKHTIN, 2016, p. 58-59).

Lembrando sempre que gêneros são enunciados, o que Bakhtin aponta nessa citação pode nos auxiliar na reflexão sobre os podcasts. $\mathrm{O}$ que sinaliza a complexidade e a riqueza desse gênero discursivo oral não está nele mesmo, mas no diálogo que estabelece com outros gêneros e com a concretude dos acontecimentos da vida. E, embora possa parecer que ouvir uma gravação em áudio e/ou vídeo seja monológico, principalmente se for de uma palestra ou aula, cabe-nos lembrar que o diálogo está nesse circuito com o que antecede e com o que sucede cada enunciado. E é nesse diálogo que o posicionamento de cada sujeito sobre o que diz, como diz e para quem diz vai constituir seu tom. 
Uma última implicação que gostaríamos de apontar é a questão dos limites da sala de aula e da escola em relação aos gêneros orais. Há uma dificuldade de se conceber o trabalho da escola com gêneros orais tendo em vista que circulam, ainda de maneira predominante, em nosso sistema escolar, uma concepção de linguagem que desconsidera a oralidade com suas especificidades e as complexas inter-relações entre o oral e o escrito. Ou assume-se que ao aluno basta dominar os conceitos de Gramática Tradicional que, automaticamente, pensando bem, falará bem e escreverá bem, ou toma-se em consideração somente os gêneros orais formais (essa postura é bem mais rara). De qualquer modo, a fala cotidiana, com os gêneros discursivos que a povoam e que nela se alicerçam, torna-se invisível, quando não desconsiderada ou menosprezada.

Podcasts não nasceram para a sala de aula, eles se constituem Opodcast comogênero discursivo como um gênero discursivo com temas diversificados, tanto no âmbito da significação, quanto do enfoque. Os podcasts produzidos no Brasil apresentam, segundo Luiz e Assis (2010), características específicas:

[...] no Brasil podcast é praticamente sinônimo de programas de áudio, devido à pouca produção de podcasts em vídeo (que, quando existem, são chamados apenas de "videocast"). Alguns fatores para essa preferência pelo podcast em áudio pode ser a facilidade de edição em comparação com um programa audiovisual e o fato de que muitos podcasts são gravados através de Skype e programas similares, e não com todos os participantes presencialmente juntos. [...]

O fato da maioria dos podcasts brasileiros surgir por iniciativas pessoais e voltados a nichos não valorizados pela "mídia de massa" faz com que ele dê suporte para o acesso à comunicação de setores que outrora eram marginalizados nesse contexto (LUIZ; ASSIS, 2010, p. 9).

Pode-se perceber que condições econômicas, de acesso à tecnologia e de inclusão/exclusão social impactam o uso, funcionamento, circulação e recepção do gênero.

Luiz e Assis mencionam em seu texto a Associação Brasileira de Podcasters, que faz pesquisa anual sobre os podcasts, perfil dos usuários, entre tantas outras informações. Destacamos aqui a pesquisa feita em 2018. No início do documento final, há os seguintes dados: 


\section{Marco Antonio \\ Villarta-Neder}

Helena Maria

Ferreira

50

"AMOSTRA: O questionário foi aplicado com 22.993 pessoas, sendo 22.691 ouvintes de podcast, dos quais $\mathbf{1 . 4 0 5}$ responderam também como produtores de podcast, e 302 não ouvintes de podcast" (PodPesquisa, 2018, p. 1). Mais adiante, no quesito "Quais são os podcasts que você mais ouve?", o documento apresenta uma tabela, da qual recortamos os podcasts com, pelo menos, $2 \%$ de audiência:

\begin{tabular}{|c|c|c|}
\hline \multicolumn{3}{|c|}{ 14.Quais são os podcasts que você mais ouve? } \\
\hline Resposta & № & $\%$ \\
\hline Nerdcast & 10.811 & $57,00 \%$ \\
\hline Não Ouvo (Não Salvo) & 4.011 & $21,20 \%$ \\
\hline Mamilos (B9) & 2.515 & $13,30 \%$ \\
\hline Anticast & 2.482 & $13,10 \%$ \\
\hline Gugacast & 2.447 & $12,90 \%$ \\
\hline Xadrez Verbal (Central 3) & 2.140 & $11,30 \%$ \\
\hline Braincast (B9) & 1.980 & $10,40 \%$ \\
\hline Matando Robôs Gigantes & 1.747 & $9,20 \%$ \\
\hline 99 Vidas & 1.739 & $9,20 \%$ \\
\hline Café Brasil & 1.726 & $9,10 \%$ \\
\hline Mundo Freak & 1.626 & $8,60 \%$ \\
\hline SciCast (Deviante) & 1.473 & $7,80 \%$ \\
\hline Decrépitos & 1.327 & $7,00 \%$ \\
\hline Rapaduracast & 1.195 & $6,30 \%$ \\
\hline Vértice (Jogabilidade) & 1.103 & $5,80 \%$ \\
\hline Dash (Jogabilidade) & 955 & $5,00 \%$ \\
\hline Minuto de Silêncio & 952 & $5,00 \%$ \\
\hline Naruhodo! (B9) & 848 & $4,50 \%$ \\
\hline MDM - Melhores do Mundo & 781 & $4,10 \%$ \\
\hline Rebobinando (Não Salvo) & 769 & $4,10 \%$ \\
\hline Rádiofobia & 756 & $4,00 \%$ \\
\hline Pelada na Net & 721 & $3,80 \%$ \\
\hline Hipster Ponto Tech & 719 & $3,80 \%$ \\
\hline Podcrastinadores & 645 & $3,40 \%$ \\
\hline Um Milkshake Chamado Wanda & 623 & $3,30 \%$ \\
\hline Loop Matinal & 595 & $3,10 \%$ \\
\hline Jogabilidade & 591 & $3,10 \%$ \\
\hline Bibotalk - BTCast & 552 & $2,90 \%$ \\
\hline Imagina Juntas (Half Deaf) & 538 & $2,80 \%$ \\
\hline MotherChip (Half Deaf) & 496 & $2,60 \%$ \\
\hline Eu tava lá & 444 & $2,30 \%$ \\
\hline Se eu fosse você (Não Salvo) & 429 & $2,30 \%$ \\
\hline Linha Quente (Jogabilidade) & 418 & $2,20 \%$ \\
\hline Papo Torto (Half Deaf) & 406 & $2,10 \%$ \\
\hline MPB - O Melhor Podcast do Brasil & 396 & $2,10 \%$ \\
\hline Ultrageek & 394 & $2,10 \%$ \\
\hline Viracasacas & 391 & $2,10 \%$ \\
\hline Salvo Melhor Juízo (Anticast) & 383 & $2,00 \%$ \\
\hline Bicuda (Não Salvo) & 379 & $2,00 \%$ \\
\hline Xorume & 378 & $2,00 \%$ \\
\hline Dragões de Garagem & 378 & $2,00 \%$ \\
\hline Escriba Café & 378 & $2,00 \%$ \\
\hline
\end{tabular}

Tabela 1 - Audiência de podcasts no Brasil. Fonte: PodPesquisa, 2018. 
É possível perceber-se rapidamente a diversidade temática dos podcasts brasileiros. Muitos desses nasceram e irão permanecer fora da sala de aula. São espaços de convivência, informação, identidades. Essa diversidade participa de maneira responsiva, em relação aos podcasts entre si e em relação a outros gêneros.

Para além da diversidade temática, podemos destacar uma proposta de sequências didáticas que exploram o trabalho com podcast em sala de aula. 0 material didático com podcast, produzido na disciplina "Reflexões sobre atuação em espaços educacionais I - Ensino de Língua Portuguesa" da Faculdade de Educação da UFJF, ministrada pela Profa. Tânia Magalhães $(2018)^{3}$, aponta para as potencialidades de análise linguístico-semiótico-discursiva do gênero em pauta. Assim, para além da organização linguística e do uso dos recursos semióticos, o material produzido abarca questões discursivas sobre a organização e o funcionamento do gênero, sendo contempladas dimensões relacionadas ao contexto de produção, ao público-alvo e suas demandas, às estratégias discursivas, ao tratamento dado aos conteúdos, aos efeitos de sentido suscitados pelas escolhas dos modos de dizer e pelo uso de determinados recursos semióticos. Essa abordagem, no nosso entendimento, denota uma concepção dialógica no estudo do gênero. Para Evaristo (2006, p. 13-14), o trabalho com a oralidade em sala de aula

\footnotetext{
requer considerar, além da materialidade fônica e gestual, alguns outros componentes, como o contexto de interação, ou seja, a situação de interação que envolve ao menos dois falantes, o planejamento discursivo e linguístico do locutor e o envolvimento entre os sujeitos em interação. Considerar o contexto de interação significa considerar a "situação, as características dos participantes da interação em foco e as estratégias por eles utilizadas durante o diálogo" (Brait: 1999, 193) como peças determinantes nesse processo. A dialogicidade é instaurada pela situação de atividade em um contexto específico e é resultado da tarefa cooperativa entre pelo menos dois interlocutores.
}

3 Exemplares da proposta de produção de material desenvolvida pela professora pesquisadora Tania Magalhães (2018), podem ser acessados em: 1) http://www.uff.br/projetodeoralidade/files/2018/06/3-Podcast-cinematogr\%C3\%A1fico-B\%C3\%A1rbara.pdf; 2) http://www.ufff.br/projetodeoralidade/files/2018/06/4-Podcast-Literacast-Bruna-e-Vitor.pdf; 3) http://www.uff.br/projetodeoralidade/files/2018/06/2-POD-CAST-Bia-e-Leticia-DEFINITIVO. pdf; 4) http://www.uff..br/projetodeoralidade/files/2018/06/2-POLITICAST-Isadora-Ludmila-e-Patr\%C3\%ADcia.pdf 
Marco Antonio

Villarta-Neder

Helena Maria

Ferreira

Podcast é um gênero discursivo oral. Mas o que é modalidade oral de uma língua, no contexto de um país, da diversidade de suas culturas e de suas identidades ? Certamente, não se limita a uma realização cotidiana simplista e mais pobre do que os gêneros discursivos escritos em situação de prestígio e poder.

Não há como ser analisado fora das múltiplas dimensões desse multiverso que é o mundo digital. E, mais do que definir-se pelo conteúdo que transmite e compartilha e pela estrutura que o compõe, caracteriza-se por essa dinamicidade multissemiótica que, no caso deste artigo, buscamos explorar com um referencial que assume como constitutivo o diálogo e a inter-relação entre o dizer e o fazer, entre os sujeitos e os sentidos.

\section{Considerações Finais}

Tivemos como objetivo, neste artigo, discutir as potencialidades e implicações teóricas, metodológicas, epistemológicas e axiológicas do gênero discursivo podcast como prática educacional. Na trajetória reflexiva que tentamos estabelecer, procuramos apontar algumas implicações e desafios.

Nesse contexto, partimos do pressuposto de que o uso de podcast como um gênero a ser trabalhado em sala de aula implica, necessariamente, considerar que "gêneros do discurso não se ensinam; vive-se dentro de gêneros do discurso" (GERALDI, 2014, p.16). Essa concepção sobressalta a relevância de abordagens metodológicas que possibilitam a criação de espaços efetivos de usos da linguagem.

Fazer usos públicos da modalidade falada demanda um exercício reflexivo que demanda escolhas: "do que falar", "de como falar" e "para quem falar". Ao realizar tais escolhas, várias habilidades são mobilizadas, tais como argumentatividade, organização textual, recursos enunciativos e multissemióticos, construção de uma imagem de interlocutor, escolhas linguístico-discursivas.

Assim, esse gênero pode permitir deslocamentos substanciais no trabalho com as práticas orais no âmbito escolar, conforme pontuado ao longo deste artigo. Em função de suas características de "tecnologia da oralidade", os podcasts evocam o conceito de enunciado, pois respondem a uma provocação e provocam outros dizeres, o que subverte a noção de passividade das mídias sociais. Produzir um podcast demanda uma preparação e um objetivo voltado para fins objetivos comunicativos 
diversos, tais como socialização de notícias, veiculação de entrevistas, difusão de programas de rádio, combinações de vários outros gêneros (exposição, música etc.) e se tornando objeto de ensino nas instituições escolares. Ao tornar-se objeto de estudo, os podcasts podem favorecer o trabalho com usos concretos em sala de aula, promovendo uma articulação entre oralidade e escrita, reduzindo práticas tradicionais de dicotomização entre essas práticas, no contexto tecnológico. Assim, ao tratarmos das potencialidades dos podcasts, é relevante explorarmos o conceito de gênero discursivo, que favorece uma abordagem que implica uma discussão acerca do caráter dialógico das práticas orais, nas quais os podcasts se constituem, sendo implicadas as condições de produção, de circulação e de recepção.

Outra questão que destacamos diz respeito às dimensões multisOpodcast comogênero discursivo semióticas dos podcasts, uma vez que essas produções podem explorar diferentes recursos/mecanismos que são indiciadores de sentido, promovendo possibilidades de análise dos usos da modalidade oral. Ao produzir um podcast, o aluno vivencia situações de uso da língua, de modo mais reflexivo, considerando o contexto enunciativo, promovendo, assim, a relação primeira entre língua e constituição do sujeito. $O$ aluno é demandado a analisar os recursos linguísticos e discursivos a serem utilizados para a construção do projeto de dizer. Assim, se o podcast for produzido no formato de áudio, os gestos e as expressões faciais (recursos visuais da modalidade oral) e os sinais de pontuação e recursos de destaque (negritos e espaçamentos próprios da modalidade escrita) terão que ser substituídos por outra forma de apresentação, que poderá ser por meio da entonação, pausas, prolongamento de vogais, repetições etc.

Se considerarmos que o ambiente de sala de aula deve refletir o espaço de interlocução, o uso de tecnologias pode dinamizar as trocas entre falantes socialmente organizados, em que os sujeitos sejam eticamente comprometidos com o seu dizer. Assim, cada recurso, como entonação, ritmo, junção de palavras etc., que integra a modalidade oral poderá ser mobilizado para produzir sentidos e constituir sujeitos em processos, efetivamente, dialógicos. 


\section{REFERÊNCIAS}

BAKHTIN, Mikhail Mikhailovitch. Gêneros do Discurso. Organização, tradução, posfácio e notas de Paulo Bezerra. São Paulo: Editora 34, 2016

BAKHTIN, Mikhail Mikhailovitch. Estética da Criação Verbal. Tradução

Marco Antonio

Villarta-Neder

Helena Maria

Ferreira

54

do russo por Paulo Bezerra. 6. ed. São Paulo: WMF Martins Fontes, 2011.

CHESTER, A.; BUNTINE, A.; HAMMOND, K.; ATKINSON, L. Podcastings in education: student atitudes, behavior and self-efficacy. Educational technology \& Society, v. 14, n. 2, p. 236-247, 2011.

ELEKAEI, Atefeh; TABRIZI, Hossein H.; CHALAK, Azizeh. Distance Education and Vocabulary Podcasting tasks: attitude in focus. Turkish Online Journal of Distance Education - TOJDE. v. 20, n. 2, p. 105-120, april 2019.

EVARISTO, M. C. A oralidade como objeto de ensino-aprendizagem: algumas considerações. 2006. $148 \mathrm{f}$. Tese (Doutorado) - Curso de Pós-graduação em Linguística Aplicada, Universidade Estadual de Campinas, Campinas, 2006.

FERREIRA, Helena Maria; VILLARTA-NEDER, Marco Antonio. Textualização e enunciação em texto multimodal: análise do video de animação Escolhas da Vida. Revista Prolingua, João Pessoa, v. 12, n. 2, p.69-83, out. 2017. Disponível em: <http://www.periodicos.ufpb. br/ojs2/index.php/prolingua>. Acesso em: 13 ago. 2019.

GERALDI, J. W. Prefácio. O pensamento bakhtiniano na educação. In. GIOVANI, F.; SOUZA, N. B. (Orgs.). Bakhtin e a Educação: a ética, a estética e a cognição. São Carlos: Pedro \& João Editores, 2014, p.13-16.

LUIZ, Lúcio; ASSIS, Pablo. O Podcast no Brasil e no Mundo: um caminho para a distribuição de mídias digitais. Anais do XXXIII Congresso Brasileiro de Ciências da Comunicação - Intercom Sociedade Brasileira de Estudos Interdisciplinares da Comunicação. Caxias do Sul, RS - 2 a 6 de setembro de 2010. 
MEDVIÉDEV, Pavel. 0 método formal nos estudos literários: introdução a uma poética sociológica. São Paulo: Contexto, 2012.

PodPesquisa. In Associação Brasileira de Podcasters. Disponível em http://abpod.com.br/podpesquisa/. Acesso em 15 ago. 2019.

VILLARTA-NEDER, Marco A.; FERREIRA, Helena M.; SALES, Raphael S. Enunciados Multissemióticos na Sala de Aula na visão bakhtiniana: Um dizer sobre dizeres e um fazer sobre fazeres. In: FRANCELINO, Pedro F.; SANTANA, Wilder K. F. (Org.) Bakhtin e o Círculo em fronteiras do discurso. São Carlos: Pedro \& João Editores, 2019.

Opodcast comogênero discursivo

VOLOCHINOV, Valentin Nicolaievitch. A construção da enunciação. 55 In: VOLOCHINOV, Valentin Nicolaievitch. A Construção da Enunciação e Outros Ensaios. São Carlos: Pedro \& João Editores, 2013. p. 157-188. Organização, Tradução e Notas de João Wanderley Geraldi. Edição e Supervisão da Tradução por Valdemir Miotello. 
